\title{
The Evolution of Human Chromosome 7 Syntenies in Eutheria, with Special Attention to Primates
}

\author{
Daniela Romagno ${ }^{1}$ and Luca Sineo ${ }^{2 *}$ \\ ${ }^{1}$ Laboratori di Antropologia - Dipartimento di Biologia Animale e Genetica - Università degli Studi di Firenze, via del Proconsolo \\ 12, 50122 Firenze, Italy \\ 2* Dipartimento di Biologia Animale - Università degli Studi di Palermo - via Archirafi 18, 90123 Palermo, Italy
}

\begin{abstract}
Genetic and cytogenetic comparison in between man and non-human primates has largely contributed to the knowledge of the evolution of the Order Primates, and in particular of man. Recently, the "Chromosome painting" approach indicated a strong conservation of syntenies in Eutheria. At present, a more precise identification of breakpoints and evolutionary related rearrangements can be obtained by BAC and locus specific in situ hybridisation. In spite to this situation the evolutionary history of different human autosomes remains a dilemma; at the same time, high resolution banded chromosome analysis confirms to be a valuable tool for the preliminary detection of fine rearrangements. This review critically describes current information concerning the evolution of human chromosome 7 orthologous in several Eutherian groups. Included in this analysis are data on species belonging to 11 orders. Nevertheless, this study has been mainly focused on Primates were we considered data from 9 species of Prosimians, 25 species of Platirrhinae, and 51 species of Catarrhinae. Chromosome 7 synteny appeared in a mammalian ancestor in a dual form, generally described as $7 \mathrm{a}$ and $7 \mathrm{~b}$ forms. These chromosomes underwent to several linespecific rearrangements in the different orders. A particular complexity in chromosome rearrangements has been highlighted in Primates. A chronologically fossil-tuned dynamic of the synteny is proposed, starting from classical and molecular cytogenetics specific landmarks which appeared throughout evolution.
\end{abstract}

Key words: Evolution, Human chromosome 7, Mammals, Primates, Syntenies.

\section{THE DEVELOPMENT OF HUMAN CHROMOSOME 7 COMPLEX SYNTENY}

Human evolution is still a central theme in contemporary biology. Palaeontological, achaeological and genetical testimonies are debated with increasing frequency and well based hypotheses to many questions have been provided. From a zoological point of view humans are encephalised primates with a complex behaviour called "culture". Many biological characteristics of modern humans evolved in a common ancestor to humans and other primate species. Comparative ethology of primates and of the entire class of Mammalia provides clues to our behavioural phylogeny.

Living primates include 200 species, with a growing complexity in phenotypical and functional characters, from prosimians to our species.

As a group, primates are surprisingly ancient; even if certain primate fossils date from Eocene period (previous Plesiadapiformes $(\dagger)$ are now included

\footnotetext{
* Corresponding author: fax +39-91-6230144; e-mail: llsineo@unipa.it.
}

in a sister order of ancestral specialised Cretaceous mammals) a late Cretaceous appearance must be considered (MARTIN 1993). As fossil records are generally rare, and in some case almost absent (as in South American tertiary harbours), comparative evolutionary biology utilises different multidisciplinary approaches, and chromosomal reconstruction of primate phylogeny is considered a valuable tool (NOVACECK 1992). The increased quality of chromosome banding and FISH technology, together with the Human genome project results provide a deep insight into human chromosomes.

FISH technology and comparative gene mapping has been widely applied for the comparative analysis of humans and different mammals species. Much effort has gone into charting genome homology between the primates from Prosimians to humans and extensive work has also been done in Ungulata, Carnivora, Edentata, Artiodactila, Lagomorpha, Cetacea and Proboscidata. This studies suggest that wide stretches of syntenic homology persist across mammalian orders (WIENBERG and STANYON 1998; O'Brien et al. 1999; Murphy et al. 2001).

In spite to this, only a very small proportion of mammalian species have been studied at any level, and large tracts of the genomes remains uncharted. 
From a chromosomal point of view, human syntenic association are clearly conservative but, on the same time, the fine genesis of many chromosomes remains to be defined as the comparative analysis of high resolution GTG banding demonstrates (RoMAGNO et al. 2004).

This review gathers all available cytogenetic information concerning the evolution of the syntenic homologous of Human chromosome 7 in Eutherians, with special attention to Primates. We then propose a chronology for the cytogenetic landmarks that characterise the phylogeny of these homologs throughout mammalian evolution.

Included in this analysis are data on eleven eutherian orders: Chiroptera (Volleth et al. 1999; VolLETH et al. 2002), Cetacea (BIELEC et al. 1998), Artiodactyla (O'Brien et al. 1999; Antoniou et al. 2002; Caetano et al.1999; Fronicke et al., 1997a; FronICKe and Wienberg 2001; SChibler et al. 1998; Goureau et al. 1996; BRUCH et al. 1996), Tubulidentata, Perissodactyla (Richard et al. 2001; RAudSEPP et al. 1996; CAETANO et al. 1999), Insectivora (O’Brien et al. 1999; Svartman et al. 2004), Rodhentia (Richard et al. 2000; Watanabe et al. 1999; Carver and Stubbs 1997; Stanyon et al. 2003), Lagomorpha (KoRstanje et al. 1999), Edentata (RICHARD et al. 2000), Carnivora (NASH et al. 1998; Fronicke et al. 1997b; WIENBERg et al. 1997; CAETANO et al. 1999; YANG et al. 2000; MuRPhy et al. 2000; Richard et al. 2000; Graphodatsky et al. 2001; Graphodatsky et al. 2002; Cavagna et al. 2000), Proboscidea (YAng et al. 2000; YAng et al. 2003; Fronicke et al. 2003), and Scandentia (RichARD et al. 2000; Muller et al. 1999 (Tab. 1).

Among Primates, in addition to Great apes, we considered 9 species of Prosimians (CARdone $e t$ al. 2002; Richard et al. 2000; Muller et al. 1997; Muller et al. 1999; StANYon et al. 2002; Masters et al. 1987; Stanyon et al. 1987), 25 species of Platirrhinae (NEusser et al. 2001; Muller et al. 2001; STANYON et al. 2000; GARCiA et al. 2002; RichaRd et al. 1996; CARLÀ CAMPa et al. 1992; Richard et al. 2000; Consigliere et al.1996; Consigliere et al. 1998; Stanyon et al. 2001; Seuanez et al. 2001; MoRESCALCHI et al. 1997; StANyon et al. 2003), in Catarrhinae we considered 20 species of Papionini (Stanyon et al. 1988; Wienberg et al. 1992; RuizHerrera et al. 2002a; Ruiz-Herrera et al. 2002b; Muller and Wienberg 2001) 8 species of Colobinae (Nie et al. 1998; Stanyon et al. 1992; Ponsì et al. 1983; KingsLey et al. 1997), 13 species of Cercopithecini (FINelli et al. 1999; Sineo et al. 1986; RIChard et al. 2000; Sineo 1986; Clemente et al. 1990; Ponsì et al. 1981; O'Brien 1993; O'Brien et al.1993; Stanyon and Sineo 1983; Romagno et al.
2004),.10 species in Hylobatidae (NIE et al. 2001; Jauch et al. 1992; Stanyon et al. 1987; DeSilva et al. 1999; Koenler et al. 1995a; KoeHLer et al. 1995b; Muller and Wienberg 2001) (Tab.2).

Eutherian mammals - In most of the species outside of primates, with the exception of rat and mouse (Watanabe et al. 1999; Carver and Stubb 1997), the synteny of human chromosome 7 and the homologous sequences are distributed on two chromosomes.

There is usually a large segment homologous to most of HSA7 and additionally a small segment associated with HSA 16 sequences, in most or in at least one of the species of every mammalian order. The small segment of chromosome 7 has proved difficult to detect and sometimes goes unnoticed by chromosome painting. This segment was overlooked in the initial painting studies in cat (WIENBERg et al. 1997), pig (GOUREAU et al. 1996) and horse (RAUDSEPP et al. 1996). It is likely that in many of the reports on various species the chromosome painting signal for this small segment probably escaped detection: Rhinolopus mehely (Chiroptera), Sores araneus (Insectivora), Ailuropoda melanoleuca, Tremarctos ornatus, Phoca vitulina, Mustelia putorius furo (Carnivora), and Tupaia belangieri (Scandentia).

The analysis of reciprocal painting as well as gene and genomic maps demonstrates that, usually, this small fragment contains sequences found in chromosome bands HSA7p22, 7q11.2, 7q21.11 and 7q22. The sequences of HSA16 with which this segment is frequently associated derive from 16p.

By definition, in humans, sequences belonging to bands $7 \mathrm{q} 11.2,7 \mathrm{q} 21$ and $7 \mathrm{q} 22$ are present together with the sequences of the larger segment of HSA7 to form a single syntenic chromosome, but this consideration have to be reconsidered on the light of new data on the BAC hybridisation and in silicio study conducted on HSA7 and othrologous in primates (Muller et al. 2004). However, in some species this synteny is secondarily fragmented and is often associated with different human chromosomal syntenies. For example a number of intra-chromosomal rearrangements was demonstrated in cattle (ANTONIOU et al. 2002) and in the cat (Murphy et al. 2000).

Primates: Prosimians - Prosimians painting data are available for two species of Galagonidae and three species of Lemuridae. In Otolemur crassicaudatus there is a possible evidence of the ancestral eutherian association HSA7/HSA16. In this species, in fact, most of the part homologous to HSA7 forms an acrocentric chromosome (OCR 6), similar in banding to PPY10q, whereas a small segment of HSA7 and part of HSA 16 are found together on another chromosome (OCR7) where they are separated by a seg- 
Table 1 - Human chromosome 7 orthologous syntenies in Mammalia with the exclusion of Order Primates.

\begin{tabular}{|c|c|c|c|c|c|}
\hline ORDER & SPECIES & CODE & $2 n$ & $\begin{array}{l}\text { Sources for comparative } \\
\text { analysis }\end{array}$ & METHODS \\
\hline \multirow[t]{8}{*}{ Chiroptera } & & & & & \\
\hline & $\underline{\text { Glossophaga soricina }}$ & GSO & $2 \mathrm{n}=32$ & Volleth et al., 1999 & ZOO-FISH \\
\hline & 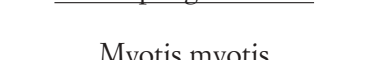 & MMY & $2 n-$ & $\begin{array}{l}\text { Richard et al, } 2000 \\
\text { Volleth et al. } 2002\end{array}$ & $\begin{array}{c}\text { Chromosome painting } \\
\text { ZOO-FISH }\end{array}$ \\
\hline & 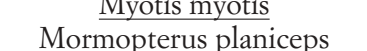 & $\begin{array}{l}\text { MINIY } \\
\text { MPL }\end{array}$ & $\begin{array}{l}2 n=44 \\
2 n=48\end{array}$ & $\begin{array}{l}\text { Volleth et al., } 2002 \\
\text { Volleth et al., } 2002\end{array}$ & $\begin{array}{l}\text { ZUO-FISH } \\
\text { ZOO-FISH }\end{array}$ \\
\hline & Hipposideros larvatus & HLA & $\begin{array}{l}2 n=40 \\
2 n=32\end{array}$ & Volleth et al., 2002 & ZOO-FISH \\
\hline & Rhinolopus mehely & RME & $2 \mathrm{n}=58$ & Volleth et al., 2002 & ZOO-FISH \\
\hline & Eonycteris spelaea & ESP & $2 n=36$ & Volleth et al., 2002 & ZOO-FISH \\
\hline & Tarsiops truncatus & TTR & $2 n=44$ & Bielec et al., 1998 & Chromosome painting \\
\hline \multirow{13}{*}{ Artiodactyla } & Bost $t$ & BTA & $2 n-60$ & 1999 & Comp \\
\hline & & B 1 A & $2 \mathrm{n}=60$ & $\begin{array}{l}\text { O'Brien et al., } 1999 \\
\text { O'Brien et al., } 1999\end{array}$ & $\begin{array}{l}\text { Comparative genomics } \\
\text { Gene mapping }\end{array}$ \\
\hline & & & & Antoniou et al., 2002 & Gene mapping \\
\hline & Ovis aries & OAR & $2 \mathrm{n}=54$ & O’Brien et al., 1999 & Comparative genomics \\
\hline & & & & Fronicke and Wienberg 2001 & Chromosome painting \\
\hline & & & & Schibler et al., 1998 & Gene mapping \\
\hline & $\frac{\text { Capra hircus }}{\underline{\text { Cans }}}$ & $\mathrm{CHI}$ & $2 \mathrm{n}=60$ & Schibler et al., 1998 & Gene mapping \\
\hline & Muntiacus muntjak vag. & MMV & $2 n=6 / 7$ & O’Brien et al., 1999 & Comparative genomics \\
\hline & Sus scrofa & SSC & $2 \mathrm{n}=38$ & Fronicke et al., 1997a & Chromosome painting \\
\hline & & & & Goureau et al., 1996 & Comparative genomics \\
\hline & & & & Bruch et al., 1996 & Gene mapping \\
\hline & & & & Goureau et al., 2001 & Chromosome painting \\
\hline & & & & Fronicke and Wienberg 2001 & Chromosome painting \\
\hline \multirow[t]{3}{*}{ Perissodactyla } & & & & & \\
\hline & Equus zebra & EZE & $2 n=32$ & Richard et al., 2001 & Chromosome painting \\
\hline & Equus caballus & ECA & $2 n=64$ & Raudsepp et al., 1996 & ZOO-FISH \\
\hline \multirow{2}{*}{ Insectivora } & $\underline{\text { Sores araneus }}$ & SAR & $2 \mathrm{n}=20$ & O’Brien et al., 1999 & Comparative genomics \\
\hline & Macroscelidae proboscidens & MPR & $2 n=26$ & Svartman et al., 2004 & Chromosome painting \\
\hline \multirow{5}{*}{ Rodhentia } & Menetes berdmorei & MBE & $2 n=40$ & Richard et al., 2000 & Chromosome painting \\
\hline & Sciurus carolinensis & SCA & $2 \mathrm{n}=40$ & Stanyon et al., 2003 & Chromosome painting \\
\hline & Rattus norvegicus & RNO & $2 \mathrm{n}=42$ & Watanabe et al., 1999 & Comparative genomics \\
\hline & Mus musculus & MMU & $2 n=40$ & Carver and Stubb, 1997 & Comparative genomics \\
\hline & & & & Stanyon et al., 1999 & Chromosome painting \\
\hline \multirow{2}{*}{ Lagomorpha } & Orictolagus cuniculus & OCU & $2 n=44$ & Korstanie & Chromosome painting \\
\hline & & & & Robinson et al., 2002 & Chromosome painting \\
\hline \multirow{2}{*}{ Edentata } & vemcinctus & & $2 n=64$ & & \\
\hline & nctus & DNO & $2 \mathrm{n}=64$ & $\mathrm{R}$ & g \\
\hline \multirow{13}{*}{ Carnivora } & Ailuropoda melanoleuca & AME & $2 \mathrm{n}=42$ & Nash et al., 1998 & Chromosome painting \\
\hline & Tremarctos ornatus & TOR & $2 \mathrm{n}=52$ & Nash et al., 1998 & Chromosome painting \\
\hline & Phoca vitulina & PVI & $2 \mathrm{n}=32$ & Fronicke et al., 1997b & ZOO-FISH \\
\hline & Felix cattus & FCA & $2 \mathrm{n}=38$ & Wienberg et al, 1997 & Comparative genomics \\
\hline & & & & Wienberg and Stanyon, 1995 & Chromosome painting \\
\hline & & & & Wienberg and Stanyon, 1997 & Chromosome painting \\
\hline & & & & Yang et al., 2000 & Chromosome painting \\
\hline & & & & Murphy et al., 2000 & Chromosome painting \\
\hline & Panthera leo & PLE & $2 \mathrm{n}=38$ & Richard et al., 2000 & Chromosome painting \\
\hline & Canis familiaris & CFA & $2 \mathrm{n}=78$ & Yang et al., 2000 & Chromosome painting \\
\hline & Mustela vision & MVI & $2 \mathrm{n}=30$ & Graphodatzky et al., 2001 & Chromosome painting \\
\hline & & & & Graphodatzky et al., 2002 & Chromosome painting \\
\hline & M.putorius furo & MPF & $2 n=40$ & Cavagna et al., 2000 & Chromosome painting \\
\hline Tubulidentata & Orycteropus afer & OAF & $2 n=20$ & Yang et al., 2000 & Chromosome painting \\
\hline \multirow[t]{4}{*}{ Proboscidea } & & & & & \\
\hline & Loxodonta africana & LAF & $2 \mathrm{n}=56$ & Yang et al., 2000 & Chromosome painting \\
\hline & & & & Fronicke et al., 2003 & Chromosome painting \\
\hline & Elephas maximus & EMA & $2 n=56$ & Yang et al., 2000 & Chromosome painting \\
\hline \multirow{3}{*}{ Scandentia } & Tupaia chinensis & TCH & $2 n=62$ & Richard et al., 2000 & Chromosome painting \\
\hline & T. belangieri & TBE & $2 \mathrm{n}=62$ & Muller et al., 1999 & Chromosome painting \\
\hline & T. glis & TGL & $2 \mathrm{n}=60$ & Toder et al., 1992 & Comparative cytogenetics \\
\hline
\end{tabular}


Table 2 - Human chromosome 7 orthologous syntenies in Primates.

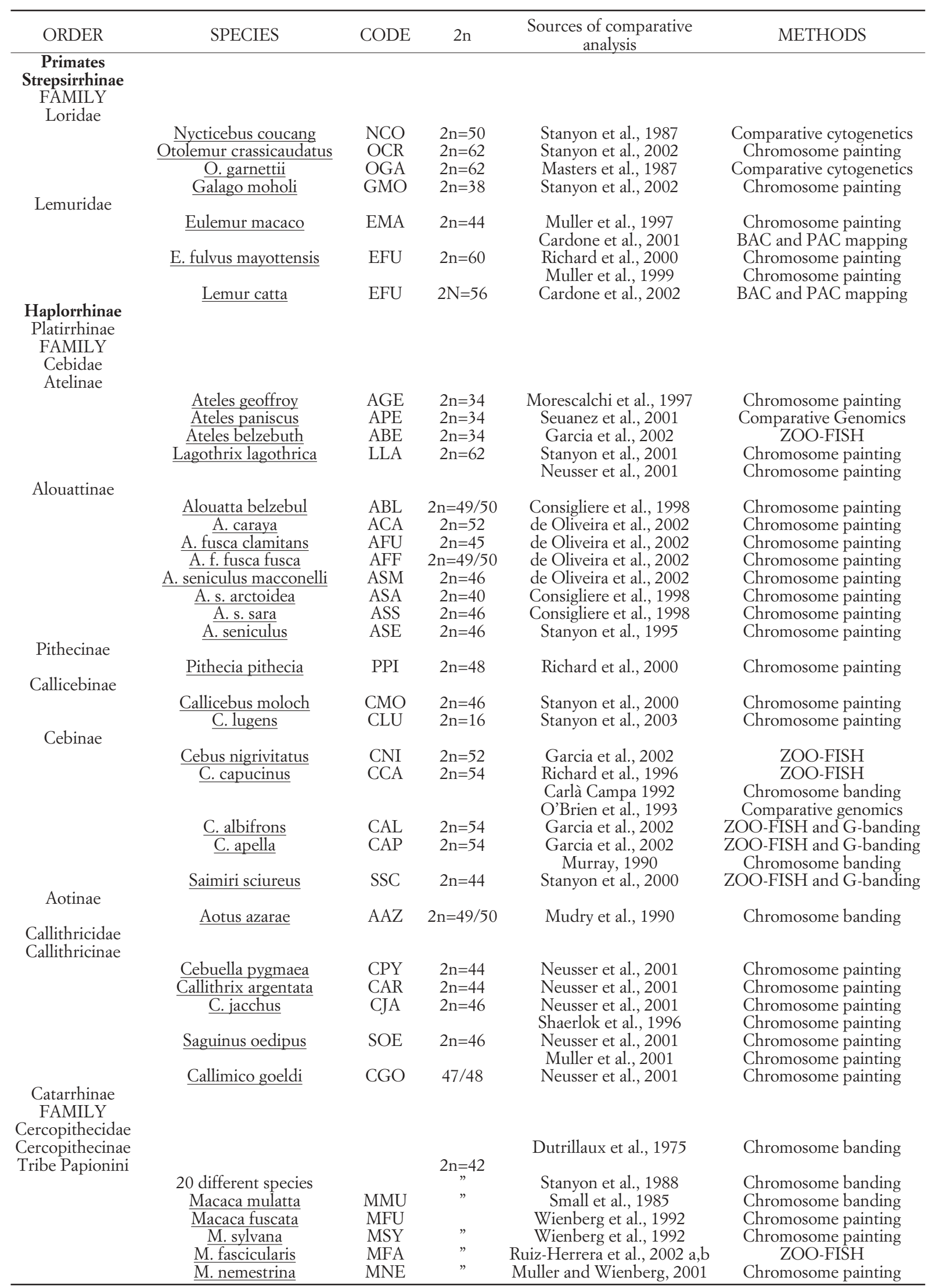




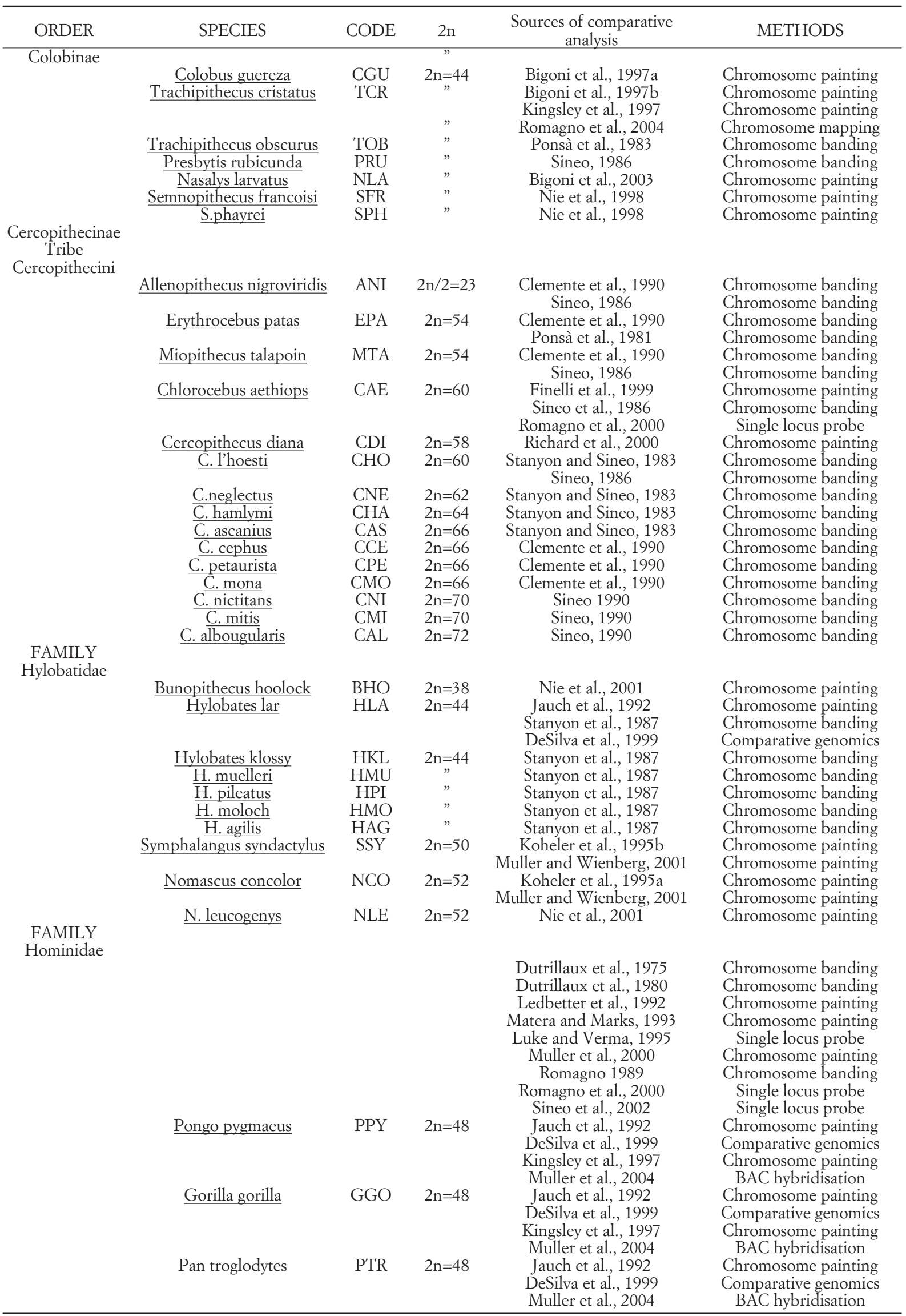


ment homologous to HSA 12 (StANYon et al. 2002). The associations along OCR7 (HSA16/HSA12/ HSA7/HSA12) make it a plausible hypothesis that an inversion disrupted the ancestral HSA7/HSA16 association, after a translocation with a segment of chromosome HSA12. Apparently, the HSA16 sequences on OCR7 derive from the 16p. The same situation may be present in Galago moholi even if HSA7 sequences have been detected only in a single chromosome. In fact, StANYON et al. (2002) suggests that the signal of the small segment of HSA7 associated with HSA16 may have escaped the detection. A very similar banding pattern in Galago garnetti (MAsters et al. 1987) and in Nycticebus coucang (StANYon et al. 1987) makes it reasonable to hypothesise that the 7/16 association will eventually be found in these species.

In Lemuridae, homologs to HSA7 are constituted by an acrocentric chromosome (Eulemur fulvus mayottensis, Lemur catta), or an arm of a metacentric chromosome (Eulemur macaco). These chromosomes all have a banding pattern similar to PPY10 (Muller et al. 1997, 1999; CARDONE et al. 2002). The remaining HSA7 sequences constitute a microchromosome in Eulemur fulvus mayottensis and Eulemur macaco (Muller et al. 1997, 1999). Possibly on the same chromosome of E. macaco, RICHARD et al. (2000) detected also the presence of another not specified human synteny. The small signal relative to HSA7 found in EFM and EMA may have gone undetected by CARDONE et al. (2002) in Lemur catta, since they did not obtain signals for HSA2 and HSA4 paints and had no signals for some chromosomal region and some micro-chromosomes. A small acrocentric in this species could be homologous to the small fragment of HSA7 synteny, which is found associated to HSA16 sequences in Eutherian mammals.

Primates: Platyrrhinae - In almost all New World primates analysed with chromosome painting most of HSA7 is constituted by a single acrocentric chromosome with a PPY10q like banding features or, in Callithrichinae and Saimiri, a submetacentric chromosome. Further, in some species it constitutes a large chromosomal segment or whole arm, associated with different syntenies (CONSIGLIERE et al. 1996; StANYON et al. 2000). The remaining small part of HSA7 is associated with HSA 5 sequences (RICHARD et al. 2000). A single hybridisation signal has been detected only in three of over twenty analysed species (two in Alouattinae, Consigliere et al 1996; one in Callicebinae, STANYON et al. 2000); however, it can not be excluded that the signal of the small part of HSA7 associated with HSA 5 sequences escaped detection.

Saguinus oedipus WCP probes tested on Alouattinae genomes (DEOliveIrA, 2002) and Lagothrix lagothricha whole chromosome probes tested on Callimico goeldii genomes (NeUsSER et al. 2001, STANYON et al. 2001) demonstrated the presence of segments homologous to HSA7p22/7q11.2-7q21. The mapping of GUSB gene on Cebus capucinus chromosomes (O'Brien et al. 1993) demonstrated the presence of HSA7p22, 7q11.2 and 7q21 bands in the association with HSA5 sequences. The mapping of the PGP gene (HSA 16p) on chromosome 16 in Cebus capucinus (O'Brien et al. 1993) could be a symptom of an ancestral mammalian 7-16 syntenic retention not detected with the chromosome painting. Another sign of this ancestral association could be present in Callicebus lugens, where chromosome painting revealed the alignment on the same chromosome of HSA5, HSA7 and HSA16 sequences (STANYON et al. 2003). However, the association HSA7/HSA16 is more probably a derived trait because this chromosome has several human syntenies and HSA16 synteny is highly disrupted,

Primates: Catarrhinae - In all Papionini, a karyologically conservative group, the syntenic association HSA7/HSA21 forms chromosome number 2 (STANYON et al. 1988; WIENBERg et al. 1992; MORESCALCHI et al., 1997; Ruiz-Herrera et al. 2002 a,b; Muller and WIENBERg 2001). In the HSA7 homologous segment the banding pattern is very similar to PPY10.

In Cercopithecini, marked by high karyotypic variability, painting data are limited, and many species have been studied only with banding techniques. In Chlorocebus aethiops HSA7 sequences constitute the large acrocentric chromosome 21, with banding similar to PPY $10 \mathrm{q}$, and the small acrocentric chromosome 28 with banding similar to PPY10p. Reciprocal painting on HSA chromosomes demonstrate the presence of HSA7p21-cen, 7q21, 7q31-qter sequences on CAE 21, and 7p22, 7q11.2, $7 \mathrm{q} 22$ on CAE 28 (Finelli et al. 1999). WilliamsBeuren locus mapping confirmed the presence of $7 \mathrm{q} 11.23$ sequences on chromosome CAE 28 (RoMAGNO et al. 2004). Other gene mapping data, however, reveal that sequences of HSA7q21.11 and of HSA7q22 are also present, respectively, on CAE 28 and CAE 21 (O'BrIEN 1993). Reciprocal painting data demonstrated almost the same situation for chromosome 21 and 25 in Erytrocebus patas (STANYoN, personal communication). In this case, however, it is evident the presence of HSA7q22 sequences on both chromosomes EPA25 and EPA21. In Cercopithecus l'hoest $i$ the banding analysis shows two chromosomes, similar to CAE 21 (or EPA21) and CAE 28 or (EPA 25). This data confirm a period of common evolution to these three species like previously hypothesised on the basis of R-banding (DUTRILLAUX et al. 1982) and molecular data (Tosi et al. 2003). 
Chromosome painting in Cercopithecus diana shows a single signal on a submetacentric chromosome (RICHARD et al. 2000) with banding identical to PPY10; the same situation, even if without a molecular validation, can be hypothesised for Allenopithecus nigroviridis, a species thought to be the closest guenon to the ancestral stock of Cercopithecinae on the basis of karyological evidences (Dutrillaux et al. 1980), morphological and molecular data (Strasser and Delson 1987; Tosi et al. 2003).

In Cercopithecus neglectus HSA 7 synteny is conserved in a single submetacentric chromosome (STANYON personal communication) with a banding pattern surprisingly similar to the homologous in Gorilla. A chromosome with very similar banding is also present in Cercopithecus mona, Cercopithecus cephus, Cercopithecus ascanius, Cercopithecus petaurista, Cercopithecus nictitans and Cercopithecus mitis (Sineo 1986). As these species on the basis of R-banding (Dutrillaux et al. 1982; Clemente et al. 1990) and molecular data (Tosi et al. 2003) are grouped together in the reconstruction of the phylogenetic tree of Cercopithecini; it is possible that they share a common pericentric inversion in an ancestral homologous to HSA7 similar to that of Allenopithecus nigroviridis (ANI) and Cercopithecus diana (CDI). The same inversion probably occurred in the lineage leading to African great apes and man, and it would represent an example of convergent evolution at least at the light microscope level of resolution.

In the other species considered it was not possible identify a clear banding homology.

Colobinae monkeys analysed with the painting approach, belonging to genera Trachypithecus, Colobus, Nasalis and Semnopithecus, present HSA 7 synteny in a single chromosome, similar in banding pattern in the different species (NIE et al. 1998) but different from any HSA7 homologous of the other species of Cercopithecidae. William-Beuren locus and subtelomeric HSA7p probe mapping in Trachypithecus cristatus and other primates (Romagno et al. 2004; KINGSLEY et al. 1997) reveal the occurrence of complex intrachromosomal rearrangements (RoMAGNo et al. 2004); in Trachypithecus, Colobus and Semnopithecus a p-terminal area without any hybridisation signal was reported (NIE et al. 1998).

Among the lesser apes, only Hylobates lar presents a single signal for HSA 7 synteny on the qarm and on the proximal part of the p-arm of a large metacentric chromosome (JAUCH et al. 1992). The banding pattern of this region is identical to PPY10. The WS probe maps in the pericentromeric region of the p-arm indicating that in this area there are sequences of HSA7q11.23 (DE SiLva et al. 1999). The other gibbon species with $2 \mathrm{n}=44$ show identical banding patterns and likely the same hybridisation pattern. In $H$. hoolock most of HSA 7 synteny is associated with other human syntenies in a submeta- centric chromosome (NIE et al. 2001) and the banding pattern is similar to PPY 10q. The small remaining part is translocated to another chromosome. In $H$. concolor and $H$. syndactylus HSA7 synteny was variously fragmented into three segments.

After the synteny of human chromosome 7 (HSA7) was established, as a chromosome similar to Pongo pygmaeus chromosome 10, it was then subject to a pericentric and then a paracentric inversion in the phylogenetic line leading to $H$. sapiens. Specifically, high resolution chromosome analysis demonstrated that chromosome 7 in homo and chimpanzee differ from the orthologous in Gorilla by a paracentric inversion which differ from the ancestral like by a pericentric inversion. It derives that the gorilla chromosome represent the intermediate form that characterise the hominoid lineage (YUNISH and PRAKASH 1982).

Muller and colleagues (MulLER et al. 2004) recently demonstrated that pericentric and paracentric inversions that characterise hominoid lineage occurred in 7p22.1 and 7q22.1 breakpoints (respectively at $6.8 \mathrm{Mb}$ and at $97.1 \mathrm{Mb}$ on the reference sequence map) and 7q11.23 and 7q22.1 (respectively at 76.1-76.3 Mb and 101.9 Mb on the reference sequence map). The analysis pointed the attention to the importance of a fine $\mathrm{BAC}$ mapping and, more importantly, revealed the presence of "large segmetal duplications" of low copy repeats (LCRs) flanking these hot spots. Segmental duplications have been already described in association with several important rearrangements in primates (SARMONTE et al. 2002) and their presence, prior to the rearrangement (their spread in occurrence of the rearrangements seems a less probable event) and their causative role in chromosomal rearrangements has been proposed (MULLER et al. 2004).

Even if chromosome painting shows that chromosome 7 synteny is highly conserved in higher Primates, banding comparison BAC mapping and single locus mapping (as the Williams-Beuren syndrome locus; WS - HSA7q11.23), among the Hominoidea and Cercopithecoidea, suggest the occurrence of phylogenetically significant rearrangements (i.e. pericentric and paracentric inversions), undetected with whole chromosome paints (RoMAGNO et al. 2004).

\section{DISCUSSION}

An analysis of the data presented above allows us to hypothesise the presence in the ancestral eutherian karyotype, of an acrocentric chromosome containing most of HSA7 (Richard et al. 2000; MurPHY et al. 2001). A small, probably submetacentric, chromosome would contain the rest of HSA7 associated 
with HSA16p sequences. This last chromosome presumably contains sequences related to chromosome bands HSA7p22, 7q11.2, 7q21.11 and 7q22 bands.

The presence, in Prosimians, of a large ( $7 \mathrm{a}$ ) and a small (7b) acrocentric chromosome containing only HSA7 sequences (MulLer et al. 1997, 1999) could indicate that the ancestral HSA7/HSA16 association was disrupted very early, during primate evolution. Muller et al. (1999) proposed, on painting data in Tupaia belangieri, the presence of a single submetacentric, ancestral chromosome. On the contrary, RICHARD et al. (2000) proposed two chromosomes in the ancestral primate homologous to segments of HSA7: a large acrocentric chromosome and a small acrocentric chromosome. The small acrocentric chromosomes probably contains the same sequences associated with HSA16p in the ancestral eutherian karyotype. This last hypothesis is based, first, on the presence of a large and a small acrocentric chromosomes entirely composed of HSA7 sequences in Strepsyrrhini, and, second, on the detection of two signals produced by HSA7 probes in Tupaia chinensis, with the smaller acrocentric associated with HSA16 sequences. As ToDER et al. (1992) affirm that banding of Tupaia belangieri and Tupaia chinensis chromosomes is identical, it is likely that the small signal concerning HSA7 sequences in Tupaia belangieri escaped detection in MULLER et al. (2001).

The situation becomes even more complex if we consider the more recent data on Galagonidae (Stanyon et al. 2002). These data open the possibility that the small chromosome with HSA7/HSA16 association was also present in the primate ancestral karyotype. This hypothesis implies the occurrence of two independent fission events, which disrupted the HSA7/HSA16 association in lemurs and in the lineage leading to simians, as it has not been found in any analysed primate species. Reciprocal painting, subchromosomal probe and mapping data on Otolemur and Galago, together with painting analysis on a larger number of prosimians species, will be necessary to definitively elucidate the situation.

In the ancestral karyotype of New World Monkeys we can hypothesise the presence of an acrocentric chromosome, with most part of HSA7 synteny similar to that of prosimians ancestral karyotype, and of a submetacentric chromosome with the remaining part of HSA7 associated with HSA5 synteny, generated by a translocation (RICHARD et al. 2000; NEUSSER et al. 2001; and STANYON et al. 2003). This new syntenic association, which in some species comprises only a part of HSA5, secondarily underwent different translocations in various species. An inversion involving the HSA5/HSA7 association in a common lineage leading to Atelinae and Alouatti- nae, or independently in the two subfamilies, could have led to the alignment HSA7-HSA5-HSA7 observed in most of the Alouattine species and all Atelinae species. Reciprocal painting (Neusser et al. 2001; Muller et al. 2001) and gene map data (O'Brien et al. 1993) demonstrated the involvement of HSA7p22, 7q11.2 and 7q21 bands in the association with HSA 5 sequences; this could confirm the homology with the HSA7 segment associated with HSA16 sequences in the ancestral eutherian karyotype.

In the ancestral karyotype of Old World Monkeys, HSA7 sequences constitute a single chromosome, which was probably similar to PPY10. This chromosome could be derived from the fusion of two primates ancestral chromosomes similar to those proposed by RicHARD et al. (2000).

During the evolution of Cercopithecini after the divergence of $A$. nigroviridis and $C$. diana, the ancestral chromosome underwent a pericentric inversion in the lineage leading to the other arboreal species with the formation of a chromosome similar to HSA7 homologs in Gorilla, and a fission in the linage leading to the terrestrial species. Further, even in consideration of the very low probability of back mutations with recurrent breakpoints, we have to consider that this last rearrangement could have restored in these species the ancestral primate.

A very similar submetacentric chromosome, containing the whole HSA7 synteny, is present in all Colobinae studied. This indicate this synteniy as the ancestral form for this group. This chromosome indeed has a peculiar banding pattern, possibly derived from the ancestral Catarrhinae form by a pericentric inversion, and other complex intrachromosomal rearrangements. In Papionini the ancestral HSA7 chromosome underwent a translocation with to form and an association with the homolog to HSA21.

In Hylobatidae the ancestral HSA7 chromosome was probably unchanged in respect to that of the ancestral Old World Monkey karytoype. It underwent a translocation with a chromosomal segment containing HSA2 sequences in Hylobates lar "group species" and a fragmentation in two (H. hoolock) or three segments (H. syndactylus and $H$. concolor) which are found associated with different human syntenies in various species.

A chromosome similar to PPY10 and therefore similar to Catarrhinae ancestral HSA7 chromosome was probably present in the ancestral karyotype of Hominoidea. This chromosome was involved in a pericentric inversion in the common lineage leading to Gorilla, Pan and Homo and a paracentric inversion in the lineage leading to Pan and Homo. 


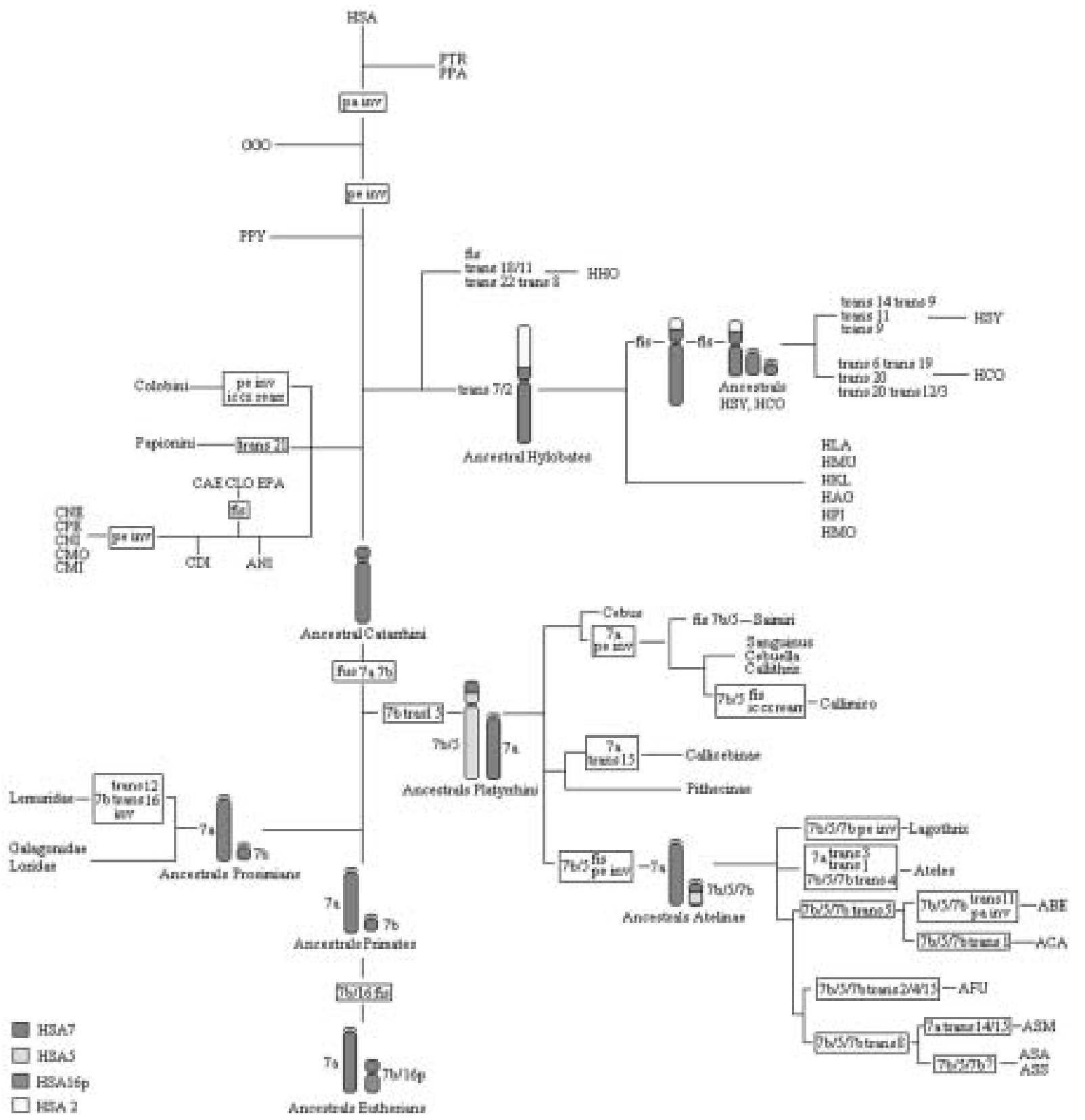

Fig. 1 - The proposed sequence of the rearrangements occurred during Primate evolution. The tree starts from the presumed ancestral Eutherian chromosomes.

Legend: fis=fission, trans=translocation, pe inv=pericentric inversion, pa inv=paracentric inversion, ic cx rear=complex intra-chromosomal rearrangement.

$\mathrm{ASS}=$ Alouatta seniculus sara, $\mathrm{ASA}=$ Alonatta seniculus arctoidea, $\mathrm{ASM}=$ Alonatta seniculus macconelli, $\mathrm{ABE}=$ Alouatta belzebul, $\mathrm{CNE}=$ Cercopithecus neglectus, $\mathrm{CMO}=$ Cercopithecus mona, $\mathrm{CPE}=$ Cercopithecus petaurista, $\mathrm{CNI}=$ Cercopithecus nictitans, $\mathrm{CMI}=$ Cercopithecus mitis, $\mathrm{CAE}=$ Chlorocebus aethiops, $\mathrm{CLO}=$ Cercopithecus lhoesti, EPA=Erythrocebus patas, HSY=Hylobates symphalangus, $\mathrm{HCO}=H y l o b a t e s$ concolor, $\mathrm{HHO}=$ Hylobates boolock, $\mathrm{HAG}=$ Hylobates agilis, $\mathrm{HKL}=$ Hylobates klossi, $\mathrm{HLA}=$ Hylobates lar, HMO Hylobates molock. HMU Hylobates muelleri, HPI Hylobates pileatus, HCO=Hylobates concolor, $\mathrm{PPY}=$ Pongo pygmaeus, $\mathrm{GGO}=$ Gorilla gorilla, $\mathrm{PTR}=$ Pan troglodytes, $\mathrm{PPA}=$ Pan paniscus, $\mathrm{HAS}=$ Homo sapiens

Chromosome 7 evolution and synteny dynamics - Even if reports of reciprocal painting and gene mapping in Primates are few, all the data lead us to hypothesize that the $\mathrm{p}$ arm of the ancestral chromosome in Catarrhinae, the associated HSA7/HSA5 sequences in Pla- tyrrhinae, and the small chromosome constituted by HSA7 sequences, present in the common ancestor of the prosimians, are homologous regions.

Further, this segment, associated with HSA16p homologous segments, characterises the common 
eutherian ancestral genome. The most consistent weakness of this hypothesis is the lack of data for HSA7q22 sequences in the small segment homologous to HSA7 associated with HSA5 in Platyrrhini. Because there are frequent rearrangements in New World monkeys which involve this region, the limitations and incongruities of available data must be considered.

In chromosomal evolution the occurrence of rearrangements from breakpoints that appear to be localised in the same regions are not rare, and chromosome 7 is not an exception. In primates, repeated breaks at the same sight could be explained by the presence of fragile sites in specific areas. For example HSA7p22 band and the homologous one in PTR, GGO and MFA, or HSA7q11.2 and the homologous band in GGO and PPY (SMEETs et al. 1990), contain a fragile site. Duplicated segments are also hypothesised to promote chromosome rearrangements and in humans and great apes there is a duplicated region in HSA7q22 (DeSilva et al. 1999; Muller et al. 2004)). Improvements in analytical technology will put light on these issues. As Muller et al. (2004) demonstrated by fine BAC mapping, "homologous" breakpoints have, in reality, a different localisation at a molecular level of resolution.

In general the data on the evolution of chromosome 7 indicate that the conservation of syntenies in mammals is important from a functional point of view (Murphy et al. 2001; Novelli et al. 1999). It could be hypothesised that gene clusters (or group of genes) share regulatory elements acting at the local level. As gene order inside conservative syntenies is often not the same it is possible that the same regulatory elements determine a different pattern of gene expression and consistent phenotypical diversity in various species in front of the syntenic conservation.

A chronology of the events in the evolution of the HSA7 synteny can be hypothesised on the base of fossil evidences and chromosome constitution of extant species (Fig. 1).

Human chromosome 7 evolved recently via a pericentric, after the divergence of African apes, and paracentric inversion before the Homo/Pan divergence. These rearrangements probably happened (SINEO et al. 2000) in the last 10-7 million of years before present.

A 7 (a) and a $7($ b) +16 p association characterised the ancestral mammalian chromosome in Cretaceous. The 7-16 fission originated in the ancestral primate situation in Eocene, even if a 7-16 association was sometime maintained or re-proposed in Prosimians.

The $7 \mathrm{a}-7 \mathrm{~b}$ fusion that characterise the ancestral base for further evolution, presumably resulted from the rise of anthropoids simians, the first evolutionary trend in Oligocene. We can put the early divergence between Platyrrhini and Catarrhyni, near 40 mya
(Ciochon and Chiarelli 1980). This divergence is chromosomally marked by a $7 \mathrm{~b}-5$ translocation in New World Primates and by the $7 \mathrm{a}-7 \mathrm{~b}$ fusion in african monkeys. This fusion signs the origin of the human chromosome 7 synteny that remained unchanged since the Dryopithecinae radiation (PILBEAM and Young 2001) and is present in Pongo, that share an ancestral chromosome 10 homologous of Human 7.

Acknowledgements - The authors thank Roscoe Stanyon for precious comments in the preparation of this review. LS greatly appreciated the suggestions of Roberto Vitturi and the help of Francesca Dumas and Daniela Carrillo.

The study was financially supported by MIUR funds to Luca Sineo (ex 60\% - 2002 - University of Palermo-Italy).

\section{REFERENCES}

Antoniou E., Gallagher D. Jr, Taylor J., Davis S., Womack J., Grosz M., 2002. - A comparative map of bovine chromosome 25 with human chromosomes 7 and 16. Cytogenet Genome Res., 97(12):128-32.

Bielec P.E., Gallagher D.S., Womack J.E., Busbee D.L., 1998. - Homologies between buman and dolphin chromosomes detected by heterologous chromosome painting. Cytogenet Cell Genet., 81(1):18-25.

Bigoni F., Stanyon R., Koheler U., Morescalchi A.M., Wienberg J., 1997a. - Mapping homology between buman and Black and White Colobine monkey chromosomes by fluorescent in situ bybridization. Am. J. Primatol., 42:289-298.

Bigoni F., Koehler U., Stanyon R., Ishida T., WIENBERG J., 1997b. - Fluorescence in situ bybridization establishes bomology between buman and silvered leaf monkey chromosomes, reveals reciprocal translocations between chromosomes homologous to buman $Y / 5,1 / 9$, and 6/16, and delineates an X1X2Y1Y2/X1X1X2X2 sex-chromosome system. Am J Phys Anthropol., 102(3):315-27.

Bigoni F., Stanyon R., Wimmer R., Schempp W., 2003. - Chromosome painting shows that the proboscis monkey (Nasalis larvatus) has a derived karyotype and is phylogenetically nested within Asian Colobines. Am J Primatol., 60(3):85-93.

Bruch J., Rettenberger G., Leeb T., Meier-Ewert S., Klett C., Brenig B., Hameister H., 1996. Mapping of type I loci from buman chromosome 7 reveals segments of conserved synteny on pig chromosomes 3, 9, and 18. Cytogenet Cell Genet., 73(3):164-7.

Caetano A.R., Shiue Y.L., Lyons L.A., O’Brien S.J., Laughlin T.F., Bowling A.T., Murray J.D., 1999. - A comparative gene map of the horse (Equus caballus). Genome Res., 9(12):1239-49.

Cardone M.F., Ventura M., Tempesta S., Rocchi M., Archidiacono N., 2002. - Analysis of chromosome conservation in Lemur catta studied by chro- 
mosome paints and BAC-PAC probes. Chromosoma, 111 (5): 348-356.

Carlà Campa M.C., Stanyon R., 1992. - Sequence of late DNA replication in Cebus capucinus chromosomes and a standardized G-banded karyotype. Am. J. Primatol., 28: 205-212.

Carver E.A., Stubbs L., 1997. - Zooming in on the buman-mouse comparative map: genome conservation re-examined on a high-resolution scale. Genome Res., 7(12):1123-37.

Cavagna P., Menotti A., Stanyon R., 2000. - Genomic bomology of the domestic ferret with cats and bumans. Mamm Genome, 11(10):866-70.

Ciochon R.L., Chiarelli A.B., 1980. - Evolutionary Biology of the new World Monkeys and Continental Drift. Ciochon, R.L., Chiarelli A.B Editors, New York, Plenum Press.

Clemente I.C., Ponsà M., Garcia M., Egozcue J., 1990. - Chromosome Evolution the Cercopithecidae and its relationship to Human fragile sites and neoplasia. Int. J. Primatol., 11(4): 377-399.

Consigliere S., Stanyon R., Koehler U., AgoraMOORTHy G., WienBerg J., 1996. - Chromosome painting defines genomic rearrangements between red howler monkey subspecies. Chromosome Res., 4(4):264-70.

Consigliere S, Stanyon R, Koehler U, Arnold N, WIENBERg J., 1998. - In situ bybridisation (FISH) maps chromosomal bomologies between Alouatta belzebul (Platyrrbini, Cebidae) and other primates and reveals extensive interchromosomal rearrangements between bowler monkey genomes. Am J Primatol., 46(2):119-33.

DeOliveira E.H., Neusser M., Figueiredo W.B., Nagamachi C., Pieczaka J.C., Sbalquieiro I.J., Wienberg J., Muller S., 2002. - The phylogeny of Howler monkey (Alouatta, Platirrbinae): reconstruction by multicolor cross-species chromosome painting. Chromosome Res., 10 (8): 669-683.

DeSilva U., Massa h., Trask B.J., Green E.D., 1999. - Comparative mapping of the region of buman 7 deleted in William Syndrome. Genome Res., 9: 428-436.

Dutrillaux B., 1975. - Etude phylogenique du caryotype bumain. - In: Sur la Nature et l'Origine des Chromosomes Humains. Monographies des Annales de Genetique. L'expansion Scientifique, Paris, p. 41-71.

Dutrillaux B., Couturier J., Chauvier G., 1980. Chromosomal evolution of 19 species or sub-species of Cercopithecinae. Ann. Genet., 23: 133-143.

Dutrillaux B, Couturier J, Muleris M, Lombard M, Chauvier G., 1982. - Chromosomal phylogeny of forty-two species or subspecies of Cercopithecoids (Primates Catarrhini). Ann Genet., 25:96-109.

Dutrillaux B., Couturier J., 1986. - Principles de l'analyse chromosomique appliquee a la phylogenie: l'exemple des Pongidae et des Hominidae. Mammalia, 50:39-52.

Finelli P., Stanyon R., Plesker R. Ferguson-Smith M.A., O'Brien P.C.M., Wienberg J., 1999. - Reciprocal chromosome painting shows that the great difference in diploid number between buman and Af- rican green monkey is mostly due to non-Robertsonian fissions. Mammalian Genome, 10:713-718.

Fronicke L., Chowdhary B.P., Scherthan H., 1997a. - Segmental bomology among cattle (Bos taurus), Indian muntjac (Muntiacus muntjak vaginalis), and Chinese muntjac (M. reevesi) karyotypes. Cytogenet Cell Genet., 77(3-4):223-7.

Fronicke L., Muller-Navia J., Romanakis K., Scherthan H., 1997b. - Chromosomal bomeologies between human, harbor seal (Phoca vitulina) and the putative ancestral carnivore karyotype revealed by Zoo-FISH. Chromosoma, 106(2):108-13.

Fronicke L., Wienberg J., 2001. - Comparative chromosome painting defines the high rate of karyotype changes between pigs and bovids. Mamm Genome, 12(6):442-9.

Fronicke L., Wienberg J., Stone G., Adams L., Stanyon R., 2003. - Towards the delineation of the ancestral eutherian genome organization: comparative genome maps of buman and the African elephant (Loxodonta africana) generated by chromosome painting. Proc R Soc Lond B Biol Sci, 270(1522):1331-40.

Garcia F., Ruiz-Herrera A., Egzocue M., Ponsà M., Garcia M., 2002. - Chromosomal Homologies between Cebus and Ateles (Primates) based on ZOOFISH and G-Banding Comparisons. American Journal of Primatology, 57:177-188.

Goreau A., Yerle M., Schmitz A., Riquet J.m., MiLAN D., 1996. - Human and porcine correspondence of chromosome segments using bidirectional chromosome painting. Genomics, 36: 252-262.

Goureau A., Garrigues A., Tosser-Klopp G., LaHBib-Mansais Y., Chardon P., Yerle M., 2001. Conserved synteny and gene order difference between buman chromosome 12 and pig chromosome 5. Cytogenet Cell Genet., 94(1-2):49-54.

Graphodatsky A.S., Yang F., Serdukova N., Perelman P., Zhdanova N.S., Ferguson-Smith M.A.., 2001. - Dog chromosome-specific paints reveal evolutionary inter- and intrachromosomal rearrangements in the American mink and buman. Cytogenet Cell Genet., 94(1-2):49-54.

Graphodatsky A.S., Yang F., Perelman P.L., O’Brien P.C., Serdukova N.A., Milne B.S., Biltueva L.S., Fu B., Vorobieva N.V., Kawada S.I., Robinson T.J., Ferguson-Smith M.A., 2002. - Comparative molecular cytogenetic studies in the order Carnivora: mapping chromosomal rearrangements onto the phylogenetic tree. Cytogenet Genome Res., 96(1-4):137-45.

Jauch A. Wienberg J., Stanyon R., Arnold N., ToFAnelli S., Ishida T., Cremer T., 1992. - Reconstruction of genomic rearrangements in great apes and gibbons by chromosome painting. Proc. Natl. Acad. Sci. USA, 89:8611-8615.

Kingsley K., Wirth J., van den Maarel S., Freier S., Roperts H.H., HaAf T., 1997. - Complex FISH probes for the subtelomeric regions of all buman chromosomes: comparative bybridisation of CEPH YACS to chromosomes of the Old world monkey Presbitys cristata and great apes. Cytogenetics Cell genet., 78 (1): 12-19. 
Koehler U., Largeoni F., Wienberg J., Stanyon R., 1995 a. - Genomic reorganization in the concolor gibbon (Hylobates concolor) revealed by chromosome painting. Genomics, 30(2):287-92.

Koehler U., Arnold N., Wienberg J., Tofanelli S., STANYON R., 1995b. - Genomic reorganization and disrupted chromosomal synteny in the siamang ( $\mathrm{Hy}$ lobates syndactylus) revealed by fluorescence in situ bybridization. Am. J. Phys. Anthropol., 97(1):37-47.

Korstanje R., O'Brien P.C., Yang F., Rens W., Bosma A.A., van Lith H.A., van ZutPhen L.F., Ferguson-Smith M.A., 1999. - Complete bomology maps of the rabbit (Oryctolagus cuniculus) and buman by reciprocal chromosome painting. Cytogenet Cell Genet., 86(3-4):317-22.

Ledbetter S.A., Kuwano A., Dobyns W.B., LedbetTER D.H., 1992. - Microdeletions of chromosome $17 p 13$ as a cause of isolated lissencephaly. Am. J. Hum. Genet., 50(1):182-9.

Luke S., Verma R.S., 1995. - The genomic sequence for Prader-Willi/Angelman syndromes' loci of buman is apparently conserved in the great apes. J Mol Evol., 41(2):250-2.

Martin R.D., 1993. - Primate origins: plugging the gaps. Nature, 363: 586-587.

Masters J.C, Stanyon R., Romagno D., 1987. Standardized karyotypes for the greater Galagos, Galago crassicaudatus E. Geoffroy, 1812 and G. garnettii (Ogilby, 1838) (Primates: Prosimii). Genetica, 30;75(2):123-9.

Matera A.G., Marks J., 1993. - Complex rearrangements in the evolution of hominoid chromosome XVII. J. Hum. Evol., 24: 233-238.

Morescalchi M.A., Schempp W., Consigliere S., Largeoni F., Wienberg J., Stanyon R., 1997. Mapping chromosomal bomology between bumans and the black-handed spider monkey by fluorescence in situ bybridization. Chromosome Res., 5(8):527-36.

Mudry M.D., 1990. - Cytogenetic variability within and across populations of Cebus apella in Argentina. Folia primatol., 54 (3-4): 206-216.

Muller S., O’Brien P.C.M., Fergusson-Smith M.A., Wienberg J., 1997. - Reciprocal chromosome painting between buman and prosimians (Eulemur macaco macaco and E. fulvus mayottensis). Cytogenet. Cell Genet, 78: 260-271.

Muller S., Stanyon R., O’Brien P.C., FergusonSmith M.A., Plesker R., Wienberg J. 1999. Defining the ancestral karyotype of all primates by multidirectional chromosome painting between tree shrews, lemurs and bumans. Chromosoma, 108(6):393-400.

Muller S., Stanyon R., Finelli P., Archidiacono N., Wienberg J., 2000. - Molecular cytogenetic dissection of buman chromosomes 3 and 21 evolution. Proc Natl Acad Sci USA,. 4;97(1):206-11.

Muller S., Neusser M., O’Brien P.C., Wienberg J., 2001. - Molecular cytogenetic characterization of the EBV-producing cell line B95-8 (Saguinus oedipus, Platyrrbini) by chromosome sorting and painting. Chromosome Res., 9(8):689-93.

Muller S., Wienberg J., 2001. - “Bar-coding” primate chromosomes: molecular cytogenetic screening for the ancestral hominoid karyotype. Hum Genet., 109(1):85-94.

Muller S., Finelli P., Neusser M., Wienberg J., 2004. - The evolutionary bistory of buman chromosome 7. Genomics, 84: 458-467.

Murphy W.J., Sun S., Chen Z., Yuhki N., Hirschmann D., MenotTi-Raymond M., O’Brien S.J., 2000. - A radiation bybrid map of the cat genome: implications for comparative mapping. Genome Res., 10(5):691-702.

Murphy W.J., Stanyon R., O’Brien S.J., 2001. Evolution of mammalian genome organization inferred from comparative gene mapping. Genome Biology, 2(6): reviews 0005.1-0005.8.

Murray M.D., 1990. - Cytogenetic variability within and across populations of Cebus apella in Argentina. Folia primatol., 54 (3-4): 206-216.

Nash W.G., Wienberg J., Ferguson-Smith M.A., Menninger J.C., O’Brien S.J. 1998. - Comparative genomics: tracking chromosome evolution in the family ursidae using reciprocal chromosome painting. Cytogenet Cell Genet., 83(3-4):182-92.

Neusser M., Stanyon R., Largeoni F., Wienberg J., Muller S., 2001. - Molecular cytotaxonomy of New World monkeys (Platyrrbini) - comparative analysis of five species by multi-color chromosome painting gives evidence for a classification of Callimico goeldii within the family of Callitrichidae. Cytogenet Cell Genet., 94(3-4):206-15.

Nie W., Liu R., Chen Y., Wang J., Yang F., 1998. Mapping chromosomal homologies between bumans and two langurs (Semnopithecus francoisi and $S$. phayrei) by chromosome painting. Chromosome Res., 6(6):447-53.

Nie W., Rens W., Wang J., Yang F., 2001. - Conserved chromosome segments in Hylobates boolock. revealed by buman and $H$. leucogenys paint probes. Cytogenet Cell Genet., 92(3-4):248-53.

NovaceK M.J., 1992. - Mammalian phylogeny: shaking the tree. Nature, 356: 121-125.

Novelli G, Amati F, Dallapiccola B., 1999. UFD1L and CDC45L: a role in DiGeorge syndrome and related phenotypes? Trends Genet., 15(7):251254.

O'Brien S.J., Womack J.E., Lyons L.A., Moore K.J., Jenkins N.A., Copeland N.G., 1993. - Anchored reference loci for comparative genome mapping in mammals. Nat Genet,3: 103-112.

O’Brien S.J., 1993. - Genetic Maps, Locus Maps of Complex Genomes. 6th ed., Cold Spring Harbor, N.Y. Cold Spring Harbor Laboratory Press

O’Brien S.J., Menotti-Raymond M., Murphy W.J., Nash W.G., Wienberg J., Stanyon R., Copeland N.G., Jenkins N.A., Womack J.E., MarshallGraves J., 1999. - The promise of comparative genomics in mammals. Science. 286: 458-481.

O’Brien S.J., Eisenberg J.F., Miyamoto M., Hedges S.B., Kumar S., Wilson D.E., Menotti Raymond M., Murphy W.J., Nash W.G., Lyons L.A., Menninger J.C., Stanyon R., Wienberg J., Copeland N.G., Jenkins N.A., Gellin J., Yerle M., Andersson L., Womack J., Broad T., Postlethwait J., Serov O., Bailey E., James M.R., Marshall-Graves J.A., 1999. - Genome 
maps 10. Comparative genomics. Mammalian radiations. Wall chart. Science, 286(5439):463-78.

Pilbeam D.R., Young N.M., 2001. - Sivapithecus and bominoid evolution: some brief comments. In: Hominoid evolution and climatic Change in Europe: Phylogeny of the Neogene Hominoid primates of Eurasia, Vol.2, Eds.L. de Bonis, Koufos G.D. and Andrews P. Cambridge University Press.

Ponsì M., Mirò R., Estop A.M., Egozcue J., 1981. - Banding patterns of the chromosomes of Erythrocebus patas (Schreber, 1774) compared to other primates species. Genetica, 56: 39-45.

Ponsà M., De Boer L.E.M., Egozcue J., 1983. Banding patterns of the Chromosomes of Presbytis cristatus purrbus and P. obscurus. Am. J. Primatol., 4: 165-169.

Raudsepp T., Fronicke L., Scherthan H., Gustavsson I., Chowdhary B.P., 1996. - Zoo-FISH delineates conserved chromosomal segments in horse and man. Chromosome Res., 4(3):218-25.

Richard F., Lombard M, Dutrillaux B., 1996. ZOO-FISH suggests a complete bomology between buman and capuchin monkey (Platyrrbini) euchromatin. Genomics, 36(3):417-23.

Richard F., Lombard M., Dutrillaux B., 2000. Phylogenetic origin of buman chromosomes 7, 16, and 19 and their homologs in placental mammals. Genome Res., 10(5):644-51.

Richard F., Messaoudi C., Lombard M., DutrilLAUX B., 2001. - Chromosome homologies between bumans and mountain zebra (Equus zebra hartmannae) and description of a new ancestral synteny involving sequences bomologous to buman chromosomes 4 and 8. Cytogenet Cell Genet., 93(3-4):2916.

Robinson T.J., YANG F., Harrison W.R., 2002. Chromosome painting refines the history of genome evolution in hares and rabbits (order Lagomorpha). Cytogenet Genome Res., 96(1-4):223-7.

Romagno, D., 1989. - La filogenesi del cariotipo umano. Ph. D. thesis, Università di Firenze, Biblioteche Nazionali di Roma e Firenze.

Romagno D., Chiarelli B., Guarducci S., GiovannUCCi-Uzielli M.L., Sineo L., 2000. - Chromosome mapping of GABRB3 and PML loci in Macaca and Cercopithecus indicates the mechanism of evolution of buman chromosome 15. Chrom Res, 8(8): 747-9.

Romagno D., Chiarelli B., Sineo L., 2004. - Evolution of human chromosome 7: new information from the mapping of William-Breuren locus on non buman primates chromosomes. Caryologia, 57(1): 39-43.

Ruiz-Herrera A., Ponsì M., Garcia F., Egozcue J., Garcia M., 2002a. - Fragile sites in buman and Macaca fascicularis chromosomes are breakpoints in chromosome evolution. Chrom Res, 10(1): 33-44.

Ruiz-Herrera A., Garcia F., Azzalin C., Giulotto E., Egozcue J., Ponsì M., 2002b. - Distribution of intrachromosomal telomeric sequences (ITS) of Macaca fascicularis (Primates) chromosomes and their application for chromosome evolution. Human genetics, 110 (6): 578-586.
SAmonte R.V., Eichler E.E., 2002. - Segmental duplications and the evolution of the primate genome. Nat. Rev. Genet., 3 (1): 65-72.

Shaerlok J.K., Friggin D.K., Delhanty J.D., ParRINGTON J.M., 1996. - Homologies between buman and marmoset (Callithrix jacchus) chromosomes revealed by comparative chromosome painting. Genomics, 33 (2): 214-219.

Schibler L., Vaiman D., Oustry A., GiraudDelville C., Cribiu E.P., 1998. - Comparative gene mapping: a fine-scale survey of chromosome rearrangements between ruminants and bumans. Genome Res., 8(9):901-15.

Seuanez H.N., Lima C.R., Lemos B., Bonvicino C.R., Moreira M.A., Canavez F.C., 2001. Gene assignment in Ateles paniscus chamek (Platyrrhini, Primates). Allocation of 18 markers of human syntenic groups 1, 2, 7, 14, 15, 17 and 22. Chrom Res, 9(8):631-9.

Sineo L., Stanyon R., Chiarelli B., 1986. - Chromosomes of the Cercopithecus aethiops species group: Cercopithecus aethiops (Linnaeus 1758), Cercopithecus cynosurus (Scopoli 1786), Cercopithecus pygerythrus (Cuvier 1821) and Cercopithecus sabaeus (Linnaeus 1776). Int. J. Primatol., 7:569-582.

Sineo L., 1986. - Cariologia ed evoluzione del genere Cercopithecus. Ph.D. thesis, Università di Firenze, Biblioteche Nazionali di Roma e Firenze.

Sineo L., Chiarelli B.A., Stanyon R., 2000. - Genetic aspects in Hominid Evolution. International Symposium on "Evolution of the Human Family: State of the Art "-Ramon Areces Foundation, Madrid, 11-13 March, 1998. Human Evolution, 15(1-2): 5-16.

Sineo L., Romagno D., Guarducci S., Lapini M., Giovannucci-Uzielli M.L., Chiarelli B., 2002. - Chromosome mapping of Miller-Diecker, SmithMagenis and RARA loci in Non-Human Primates: Implications in the Evolution of Human Chromosome 17. Genetica, 114:275-280.

Small M.F., Stanyon R., Smith D.G., Sineo L., 1985. - High resolution chromosomes of Rhesus macaques (Macaca mulatta). Am.J.Primatol., 9: 63-67.

SmeEts D.F., van de Klundert F.A., 1990. - Common fragile sites in bumans and three closely related primate species. Cytogenet. Cell Genet., 53(1):8-14.

Stanyon R., Sineo L., 1983. - Citotassonomia e filogenesi del genere cercopithecus. Antropologia contemporanea, 6(3): 237-252.

Stanyon R., Masters J.C., Romagno D., 1987. The chromosomes of Nycticebus coucang (Boddaert, 1785) (Primates: Prosimii). Genetica,75(2):145-52.

Stanyon R., Fantini C., Camperio-Ciani A., ChiARelli B., Ardito G., 1988. - Banded karyotypes of 20 species reveal no necessary correlation with speciation. Am J. Primatol., 16: 3-17.

Stanyon R., Wienberg J., Romagno D., Largeoni F., Jauch A., Cremer T., 1992. - Molecular and classical cytogenetic analysis demostrate an apomorphic reciprocal chromosomal translocation in Gorilla gorilla. Am. J. Phys. Anthropol., 88: 245-250.

Stanyon R., Tofanelli S., Morescalchi M. A., Agoramoorthy G., Ryder O. A., Wienberg J., 1995. 
- Cytogenetic analysis shows extensive genomic rearrangements between red bowler (Alouatta seniculus, Linnaeus) subspecies. Am. J. Primatol., 35(3):171-183.

Stanyon R., Yang F., Cavagna P., O’Brien P.C., Bagga M., Ferguson-Smith M.A. Wienberg J., 1999. - Reciprocal chromosome painting shows that genomic rearrangement between rat and mouse proceeds ten times faster than between humans and cats. Cytogenet Cell Genet., 84(3-4):150-5.

Stanyon R., Consigliere S., Muller S., MorescalCHi A., Neusser M., Wienberg J., 2000. - Fluorescence in situ bybridization (FISH) maps chromosomal bomologies between the dusky titi and squirrel monkey. Am J Primatol., 50(2):95-107.

Stanyon R., Consigliere S., Largeoni F., FergusonSmith M., O’Brien P.C., Wienberg J., 2001. Reciprocal chromosome painting between a New World primate, the woolly monkey, and bumans. Chromosome Res., 9(2):97-106.

Stanyon R., Koehler U., Consigliere S., 2002. Chromosome painting reveals that galagos have bighly derived karyotypes. Am J Phys Anthropol., $117(4): 319-26$.

Stanyon R., Stone G., Garcia M., Froenicke L., 2003. - Reciprocal chromosome painting shows that squirrels, unlike murid rodents, have a bighly conserved genome organization. Genomics, 82(2):245-9.

Stanyon R., Bonvicino C.R., Svartman M., SEUANEZ H.N., 2003. - Chromosome painting in Callicebus lugens, the species with the lowest diploid number $(2 n=16)$ known in primates. Chromosoma, 112(4):201-6.

Strasser E., Delson E., 1987. - Cladistic analysis of Cercopithecoid relationships. J. Hum. Evol., 16, 81-99.

Svartman M., Stone G., Page J.E., Stanyon R., 2004. - A chromosome painting test of the basal eutherian karyotype. Chromosome Res., 12 (1): 45-53.

Toder R., von Holst D., Schempp W., 1992. Comparative cytogenetic studies in tree shrews: (Tupaia). Cytogenet Cell Genet., 60(1):55-9.

Tosi A.J., Disotell T.R., Carlos Morales J., MelnICK D.J., 2003. - Cercopithecine Y-chromosome data provide a test of competing morphological evolutionary bypotheses. Mol Phylogenet Evol, 27:510521.

Volleth M., Klett C., Kollak A., Dixkens C., Winter Y., Just W., Vogel W., Hameister H., 1999. - ZOO-FISH analysis in a species of the order Chiroptera: Glossophaga soricina (Phyllostomidae). Chromosome Res., 7(1):57-64.
Volleth M., Heller K.G., Pfeiffer R.A., HAMEISTER H., 2002. - A comparative ZOO-FISH analysis in bats elucidates the phylogenetic relationships between Megachiroptera and five microchiropteran families. Chromosome Res., 10(6):477-97.

Watanabe T.K., Bihoreau M.T., McCarthy L.C., Kiguwa S.L., Hishigaki H., Tsuji A., Browne J., Yamasaki Y., Mizoguchi-Miyakita A., Oga K., Ono T., Okuno S., Kanemoto N., Takahashi E., Tomita K., Hayashi H., Adachi M., Webber C., Davis M., Kiel S., Knights C., Smith A., Critcher R., Miller J., James M.R., 1999. - A radiation bybrid map of the rat genome containing 5,255 markers. Nat Genet., 22(1):27-36.

Wienberg J., Stanyon R., Cremer T., 1992. - Homologies in human and Macaca fuscata chromosomes revealed by in situ suppression bybridization with buman chromosome specific DNA libraries. Chromosoma, 101(5-6):265-70.

Wienberg J., Stanyon R., 1995. - Chromosome painting in mammals as an approach to comparative genomics.Curr Opin Genet Dev., 5(6):792-7.

Wienberg J., Stanyon R., 1997. - Comparative painting of mammalian chromosomes. Curr Opin Genet Dev., 7(6):784-91.

Wienberg J., Stanyon R., Nash W.G., O’Brien P.C., Yang F., O’Brien S.J., Ferguson-Smith M.A., 1997. - Conservation of human vs. feline genome organization revealed by reciprocal chromosome painting. Cytogenet Cell Genet., 77(3-4):2117.

Wienberg J., Stanyon R., 1998. - Comparative chromosome painting of primate genomes. ILAR Journal (NIH Bethesda), 39: 77-91.

Yang F., Graphodatsky A.S., O’Brien P.C., Colabella A., Solanky N., Squire M., Sargan D.R., Ferguson-Smith M.A., 2000. - Reciprocal chromosome painting illuminates the bistory of genome evolution of the domestic cat, dog and buman. Chromosome Res., 8(5):393-404.

Yang F., Alkalaeva E.Z., Perelman P.L., Pardini A.T., Harrison W.R., O’Brien P.C., Fu B., Graphodatsky A.S., Ferguson-Smith M.A., Robinson T.J., 2003. - Reciprocal chromosome painting among buman, aardvark, and elephant (superorder Afrotheria) reveals the likely eutherian ancestral karyotype. Proc Natl Acad Sci U S A., 4;100(3):1062-6.

Yunis J.J., Prakash O., 1982. - The origin of Man: a chromosomal pictorial legacy. Science, 215: 1525 1529.

Received July 30, 2004; Accepted October 24, 2004 